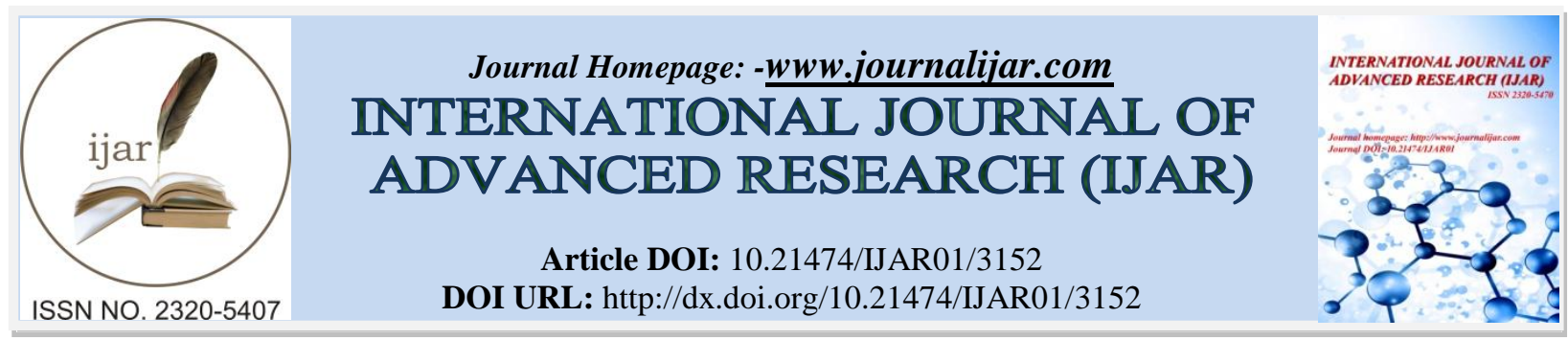

RESEARCH ARTICLE

\title{
BLEEDING PATTERN IN ABNORMAL UTERINE BLEEDING.
}

\author{
Victor Masih $^{1}$, Roma Issac ${ }^{2}$, Tapasya Dhar ${ }^{2}$ and Meenakshi Khapre ${ }^{3}$. \\ 1. Senior Resident, Blood Bank, IGMC Shimla. \\ 2. Professor, CMC Ludhiana. \\ 3. Assistant Professor, AIIMS, Rishikesh
}

\section{Manuscript Info}

Manuscript History

Received: 11 December 2016

Final Accepted: 16 January 2017

Published: February 2017

Key words:-

Abnormal uterine bleeding, Perimenopausal, endometrial specimen, menorrhagia

\section{Abstract}

Introduction:Abnormal uterine bleeding is the most common gynecological symptom in reproductive age group. The etiology varies from unknown pathology to cancer. AUB is mostly under-diagnosed due to lack of awareness of its severity. This study was carried out to find the bleeding pattern in patient with AUB.

Method:This study was conducted in the Department of Pathology, Christian Medical College, and Hospital, Ludhiana over a period of two years, which include one year of retrospective study and one year of prospective study of samples received in the department.

Result: Maximum number $343(47.7 \%)$ cases were in the age group of 41-50 years. $33.7 \%$ presented with menorrhagia.

Conclusion: AUB mostly seen in theperi-menopausal age group with avaried bleeding pattern in different studies.

Copy Right, IJAR, 2017,. All rights reserved.

\section{Introduction:-}

Abnormal uterine bleeding is a common gynecological symptom. Abnormal uterine bleeding occurring as heavy, prolonged or acyclic flow at menopausal transition or as spotting or minimal bleeding at postmenopausal period may be alarming and needs thorough evaluation, since this may be the only clinical manifestation pointing towards endometrial cancer. ${ }^{[1]}$ Whilst most patients have benign disease, athorough investigation is necessary, particularly in the peri- and post-menopausal women. ${ }^{[2]}$ Abnormal and excessive endometrial bleeding without structural pathology occurs in reproductive women of all ages but is more common in adolescent and perimenopausal women. ${ }^{[3]}$ Postmenopausally DUB is frequently associated with an atrophic endometrium. ${ }^{[4]}$ Abnormal uterine bleeding signifies various patterns menorrhagia, metrorrhagia, menorrhagia, hypermenorrhea, hypomenorrhea, oligomenorrhea and amenorrhea, It is important to know the accurate characterization of the bleeding to assist in disease-specific management. Lack of awareness of underlying bleeding disorders has led to underdiagnosis in women with abnormal reproductive tract bleeding. This study was carried out to find the bleeding pattern in patient with AUB.

\section{Method:-}

This study was conducted in the Department of Pathology, Christian Medical College, and Hospital, Ludhiana over a period of two years, which include one year of retrospective study and one year of prospective study. In the retrospective study, cases from $1^{\text {st }}$ January 2010 to $31^{\text {st }}$ December 2010 were included, while the prospective study included cases from $1^{\text {st }}$ January 2011 to $31^{\text {st }}$ December2011. A total of 719 specimens of endometrium sent as 
curetting and hysterectomy received in the department with clinical diagnosis of abnormal uterine bleeding were included in the study. The clinical details were procured from the laboratory requisition form. Only non-pregnant women were included in thestudy.

\section{Results:-}

The cases were distributed over a wide age range. The youngest patient was 18 years old while the oldest was 85 years old lady, mean age $42.5 \pm 8.2$. Maximum number $343(47.7 \%)$ cases were in the age group of 41-50 years which was the most common age group. Majority $591(82.2 \%)$ of the cases were seen in the fourth decade to fifth decades. (Table 1)

Table 1:- Age-wise distribution of cases with abnormal uterine bleeding.

\begin{tabular}{|c|c|c|}
\hline AGE (years) & No. Of cases & Percentage \\
\hline$<\mathbf{2 0}$ & 4 & 0.6 \\
\hline $\mathbf{2 1 - 3 0}$ & 51 & 7.1 \\
\hline $\mathbf{3 1 - 4 0}$ & 248 & 34.5 \\
\hline $\mathbf{4 1 - 5 0}$ & 343 & 47.7 \\
\hline $\mathbf{5 1 - 6 0}$ & 58 & 8 \\
\hline $\mathbf{6 1 - 7 0}$ & 9 & 1.3 \\
\hline $\mathbf{7 1 - 8 0}$ & 5 & 0.7 \\
\hline $\mathbf{8 1 - 9 0}$ & 1 & 0.1 \\
\hline Total & $\mathbf{7 1 9}$ & $\mathbf{1 0 0}$ \\
\hline
\end{tabular}

Out of 719 patients, $665(92.5 \%)$ were premenopausal whereas $54(7.5 \%)$ were postmenopausal.

Table 2 depicts bleeding pattern in all cases of abnormal uterine bleeding. $242(33.7 \%)$ patients presented with complaints of menorrhagia, 198 [ 27.5\%) with polymenorrhagia, $104(14.5 \%)$ patients came with complaints of metrorrhagia, $103(14.3 \%)$ patients came with complaints of menometrorrhagia, $10(1.4 \%)$ patients came with complaints of oligomenorrhoea, $8(1.1 \%)$ patients came with complaints of polymenorrhoea and $54(7.5 \%)$ patients came with complaints of postmenopausal bleeding.(Fig 1)

Figure 1:-Bleeding pattern in patients with abnormal uterine bleeding.

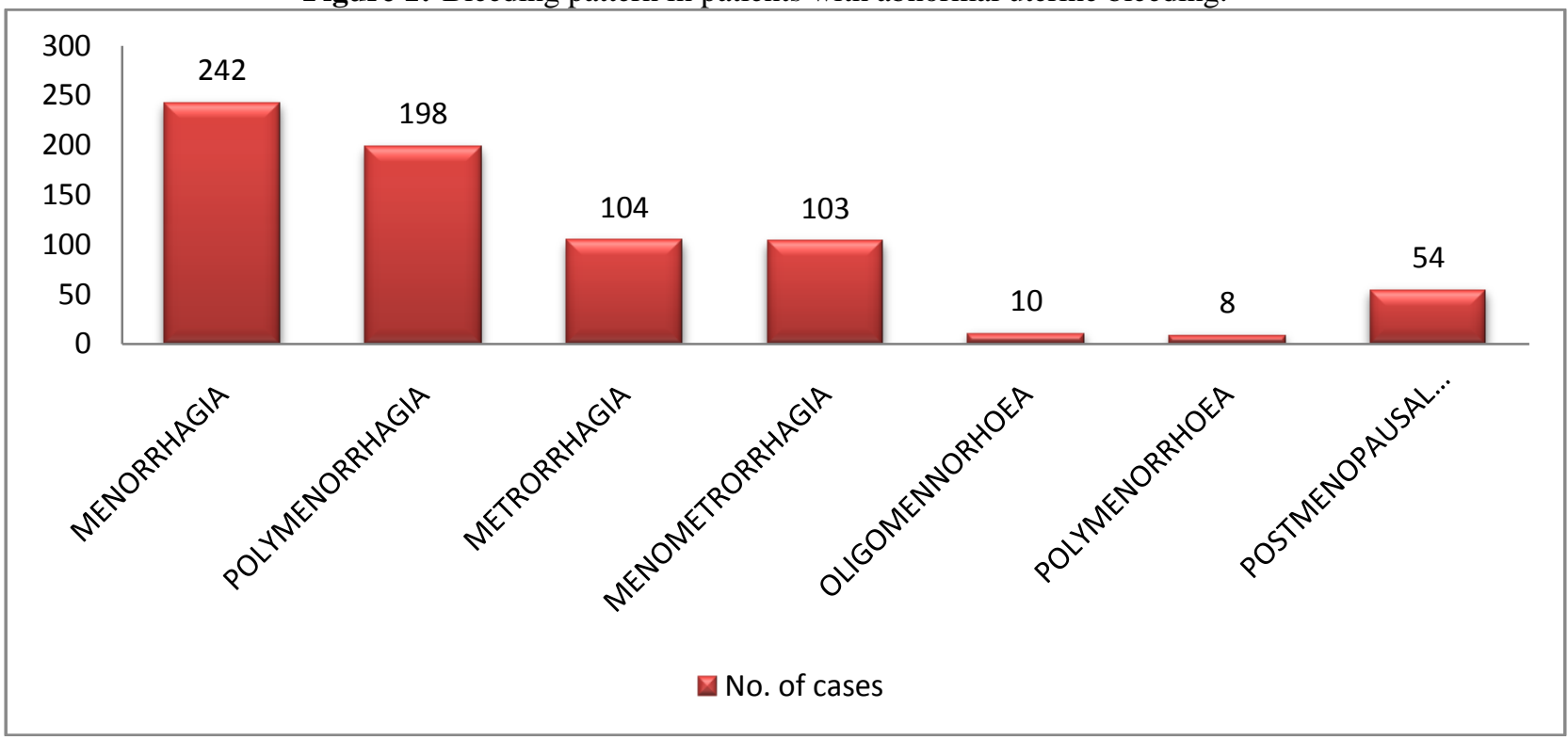

\section{Discussion:-}

The age of patients with abnormal uterine bleeding In the present study ranged from 18 to 85 years which is similar to the study done by Mirza et al 2012. ${ }^{[5]}$ The peak incidence in theage of patients $41-50$ years was seen in the $5^{\text {th }}$ decade in the present study which is same as seen byMuzaffar et al 2005, ${ }^{[6]}$ while Abdullah et al $2011^{\left[{ }^{[7]}\right.}$ had it in the $6^{\text {th }}$ decade. Because most cases are associated with anovulatory menstrual cycles, adolescents ${ }^{[8]}$ and perimenopausal women ${ }^{[9]}$ are particularly vulnerable. 
The dominant menstrual problem was menorrhagia which was similar to that reported by Jetley et al and Bharat etal. ${ }^{[10,11]}$ In a study of 400 perimenopausal women, the most common type of bleeding pattern was menorrhagia $(67.5 \%) .{ }^{[11]}$ Post menopausal bleeding was reported in only $7.3 \%$ while Bhatta et al reported in $23 \%$. This variation may be due to age pattern. ${ }^{[12]}$

\section{Conclusion:-}

$>$ The majority (47.7\%) of cases with abnormal uterine bleeding was seen in theage group of 41-50 years.

$>$ Most common bleeding patterncountered in abnormal uterine bleeding was menorrhagia. followed by polymenorrhagia.

$>$ There is variation in bleeding pattern found in different studies among various age group depicting awide range of etiological factors.

\section{References:-}

1. Bhosle A, Fonseca M. Evaluation and histopathological correlation of abnormal Uterine bleeding in perimenopausal women. Bombay Hosp J 2010;52:69-72.

2. Hunter DC, McClure N. Abnormal uterine bleeding: an evaluation endometrial biopsy, vaginal ultrasound, and outpatient hysteroscopy. The Ulster Med J 2007; 70:25-30.

3. Sharma JB. Dysfunctional Uterine Bleeding (DUB). Obstet and Gynecol Today 2000;5:20-25.

4. Davey DA. Dysfunctional Uterine Bleeding. In: Whitfield CR, ed, Dewhurst's Textbook of Obstetrics and Gynaecology for Postgraduates $7^{\text {th }}$ ed. Glasgow: Blackwell Science 1997:590-608.

5. Mirza T, Akram S, Mirza A, Aziz S, Mirza T, Mustansar T. Histopathological Pattern of Abnormal Uterine Bleeding in Endometrial Biopsies. Journal of Basic \& Applied Sciences 2012;8:114-17.

6. Muzaffar M, Akhtar KAK, Yasmin S, et al. Menstrual irregularities with excessive blood loss: a clinicopathologic correlation. J Pak Med Assoc. 2005;55:486-489. [PubMed]

7. Abdullah LS, Bondagji NS: Histopathological Pattern of Endometrial Sampling Performed for Abnormal Uterine Bleeding. Bahrain Med Bull 2011; 33(4): $1-6$

8. Bennett AR, Gray SH. What to do when she's bleeding through the recognition, evaluation, and management of abnormal uterine bleeding in adolescents. CurrOpinPediatr. 2014 Aug. 26 (4):413-9. [Medline]

9. Rezk M, Masood A, Dawood R. Perimenopausal bleeding: Patterns, pathology, response to progestins and clinical outcome. J ObstetGynaecol. 2015 Jul. 35 (5):517-21. [Medline]

10. Jetley S, Rana S, Jairajpuri ZS. Morphological spectrum of endometrial pathology in middle-aged women with atypical uterine bleeding - a study of 219 cases. J Midlife Health. 2013;4:216-20.,

11. Bharat Talukdar1 ,RashmiRekhaGoswami ,SangitaMahela, Noor Islam Ahmed3, theHistopathological pattern of endometrium in abnormal uterine bleeding of perimenopausalwomen ,International Journal of Reproduction, Contraception, Obstetrics and Gynecology Int J ReprodContraceptObstet Gynecol. 2016 Apr;5(4):1162-1166 www.ijrcog.org )

12. Bhatta S, Sinha AK. Histopathological study of endometrium in abnormal uterine bleeding. J Pathol of Nepal 2012;2:297-300. 